\title{
Lexical Abstractness and Other Factors in the Comprehension and Appreciation of Poetry in English
}

\author{
A.O. FANIRAN, Ph.D. \\ Department of English \& Literary Studies \\ Lead City University \\ Ibadan \\ O.A. Faniran, Ph.D. \\ Department of Languages and Linguistics \\ Kings University \\ Ode-Omu
}

\begin{abstract}
In this paper, we define lexical abstractness and examine the part which it plays in the comprehension and appreciation of poetry in English. The paper gives the formula for calculating the lexical abstractness of a poem and, indeed, of any text, and argues that the more lexically abstract a poem, the more difficult it is most likely to be for students to comprehend and appreciate. Other factors seen as affecting students' comprehension and appreciation of poetry are lexical density and new word density. The paper then defines these factors and gives the formula for measuring each of them. Three assumptions underline the study: the higher the lexical abstractness of a poem or text, the more difficult it will be for students to comprehend and appreciate; the higher the lexical density of a poem or text, the easier it will be for them to comprehend and appreciate; and lastly, the more the new or unknown words in a poem, the more difficult the poem will be for students to comprehend and appreciate. In view of the above, therefore, we recommend that teachers that handle the poetry aspect of Literature either at the secondary or tertiary level of education should consider all these factors before presenting this genre of literature to their students.
\end{abstract}

Keywords: poetry, lexical abstractness, lexical density, comprehension, appreciation, factors.

\section{Introduction}

Poetry is one of the three branches of literature, the two others being drama and prose. Of these three literary genres, the one often regarded by students as the most difficult is poetry (Oyetunji, 1974, Faniran, 1988, Faniran, 2004). Chief Examiners in Literature in English in both the West African Examinations Council (WAEC) and National Examinations Council (NECO) have often reported that candidates score low marks in poetry compared to their scores in drama and prose. Teachers of poetry too are not oblivious of the difficulty encountered in this notoriously perplexing genre of literature. In other words, it is not only students that express this apprehension over the difficulty they encounter in the appreciation of poetry. Quite interestingly, teachers of the subject, according to Vincent (1979), express this worry too. The poetry aspect is generally regarded by both teachers and students as almost an uphill task to successfully teach and learn.

In his Foreword to the book, "Comprehensive Notes, Questions and Answers on Selected Poems" by Izinyon (1987), Obayan (1987) opines that:

Nigerian students, contrary to popular belief, have problems with poetry, even as composed by fellow Africans. A couple of the characteristics of this literary genre make this so. First, poetry is a highly condensed form of self-expression and so, words, lines, and entire stanzas give just little indications of the message they are intended to convey ....

Similarly, Izinyon (1987: 9) wryly remarks that, as a result of the lexical abstractness of the language of poetry, many students: 
... shudder and get mentally discouraged at the mere sight of statements put in verse.

They think that there is something esoteric about poetry, something mystic and incapable o under- standing by the non-poet. The sad result is that students run away from studying poetry which in major part of their literature course. Consequently, the yearly in-take into the department of English at the H.S.C / G.C.E 'A' Level courses and ultimately at the University level is compara-tively low.

Lastly, Tucker (1973) posits that students in all countries of the world generally find poetry very difficult to appreciate. A number of reasons, which will be discussed later in this study, have been proffered for the notorious difficulty of poetry. We seek, in this paper, to examine the part which lexical abstractness plays in students' comprehension and appreciation of poetry. Other factors seen as playing a very important role in this matter are lexical density and new word density. These three factors are defined and the formula for calculating each of them is given. The following are the assumptions which underline this study: (i) the higher the lexical abstractness of a poem or a text, the more difficult it will be to comprehend and appreciate (ii) the higher the lexical density of a poem or text, the easier it will be to comprehend and appreciate (iii) the more the new or unknown words in a poem, the more difficult the poem will be for learners to comprehend and appreciate. One of our recommendations is that the teachers of poetry should consider the lexical abstractness of a poem as well as its new word density and deal with these variables before presenting the poem to their students so that the learners can easily comprehend and appreciate it without much effort.

\section{Definition of Terms}

We shall attempt to define the key terms in the title of this paper so that the general readers, not just linguists or literary experts, can easily follow the kernel of this paper. The term "lexical" is an adjective formed from the noun "lexis", which means vocabulary or the totality of the words of a language. Abstractness is a noun formed from the adjective "abstract", which means general rather than particular. In more specific terms, abstract is the opposite of concrete. A word can thus be abstract or concrete, according to traditional grammar.

A concrete word is one that evokes visual images or mental pictures and, for this reason, they are easy to understand and remember. Abstract words, on the other hand, evoke no images or mental pictures and, consequently, they are often difficult to understand. A factor in anything is what must be considered in bringing it about. Comprehension means understanding fully (Faniran).

Literary appreciation refers to the means of understanding all the nuances and shades of meaning in a literary work (Ibitola, 2009: 25). Ibitola (ibid), for instance, warns that anyone who hopes to be able to attempt a literary appreciation of any text successfully should put the following basic principles in perspective: the context of the text, its effectiveness, its setting and the central themes or ideas which the text symbolizes.

It is also necessary to distinguish between two other types of words, namely, lexical words and function words. According to Francis (1970: 64), lexical words are "words from the general vocabulary" and function words are those that have "functional or structural meanings".

Yule (1994: 61) employs the term "lexical morphemes" for what Francis (1970) and other linguists call lexical words. It should be noted that the two terms, "lexical morphemes" and "lexical word" are the same except that lexical morphemes include linguistic forms that cannot stand alone as words. Such linguistic forms or lexical morphemes include the noun plural morpheme (-s or -es), the past tense morpheme (-d or -ed), the present participle morpheme (-ing), the adjective morpheme (-er) e.t.c.

Yule (ibid) defines the two types of words in clearer terms. According to him, lexical morphemes are nouns, verbs, adjectives and adverbs "which we think of as the words that carry the content of the message which we convey". He gives the following as examples of lexical morphemes: man, house, tiger (nouns); sad, long, sincere, yellow (adjectives); and open, look, follow, break (verbs). Yule (ibid) therefore, calls the other types of words "functional morphemes" and gives the following as examples of such morphemes: when, but, on, because, near, above, the, in, that and it. From these examples, it can be inferred that the set of functional morphemes consists largely of the grammatical or structural words in the language, such as conjunctions, prepositions and articles.

The term "poetry" has been defined in many ways. Osisanwo (1984) and Olasehinde's works (1994) contain lists of definitions of poetry and the names of the poets or literary critics who gave definitions. Osisanwo (1984) for instance, cites the following definitions of poetry. 
(1) Poetry is the imaginative expression of strong feelings usually rhythmical... the spontaneous overflow of powerful feelings recollected in tranquillity- William Wordsworth

(2) It is the record of the best and happiest minds - P.B. Shelly,

(3) It is the art which uses words as both speech and song to reveal the realities that the senses record, the feelings salute, the mind perceives and the shaping of the imagination orders - Babette Deutsch

(4) Absolute Poetry is the concrete and artistic expression of the human mind in emotional and rhythmical language - Theodore Watts Denton

\section{Below are the definitions cited by Olasehinde (1994)}

(5) The poem is a statement in words about human experience.... The poet has to employ both concepts and connotations as efficiently as possible - Yor Winters.

(6) Poetry is words put into a pattern sufficiently marked to distinguish the writing from prose.... It is distinguished by a heighted use of language $-\mathrm{W}$. Nowottny.

(7) Poetry is the sort of writing stimulated by emotions expressing a deep feeling that cannot be well expressed in ordinary writing - O. Ogunyemi,

There are recent definitions of, and comments on, poetry although they are not completely different from those listed above. For instance, the Oxford Advanced Learner's Dictionary. (International Student's Edition, 2015) defines poetry as a piece of writing in which words are chosen for their sounds and the images that they suggest, not just for their obvious meanings. Okesipe and Okolo (2013: 5) define the term as "a form of literature that is characterized by the use of beautiful language that is imagistic, imaginative and expressive of human emotions". Before proffering his own definitions, Igudia (2015) warns that finding a definition that both identifies all the elements of poetry and distinguishes them from prose and drama is almost impossible. He thereafter gives what he considers to be "an easier and more practicable" definition: "poetry is a piece of writing with elevated style" (p.643).

Ayoola (2007: 320) makes the following comment on the term "poetry". According to him, it is the genre that predicates the other genres of literature". Abiola (2014: 11) remarks that "poetry is perhaps the only literary genre that is incontestably basic to all world cultures". Abiola comments further and says "although there is still a debate in certain academic circles on whether some cultures, especially traditional African cultures, have a developed drama, it is difficult to sustain the argument that a culture has no developed poetry. In fact, in traditional Africa, poetry is an everyday preoccupation... it performs innumerable functions, literary and extraliterary, and it is the main vehicle for apprehending the universe".

Also commenting on the idiosyncratic peculiarities of poetry, Vincent (1979: 219) avers that:

$\ldots$ is a sophisticated art form and makes the greatest aesthetic

Demands on the reader, calling far for more experiential involve-

ment than most people have the imaginative capacity for or care

to work themselves into.

The summary of all the definitions above about poetry is that it is a literary work which is distinguished by its peculiar form, its heightened, compressed, elevated and mostly figurative language.

\section{The Meaning of Lexical Abstractness and The Lexical Abstractness Formula}

The lexical abstractness of a text including poetry is the percentage of abstract lexical words in the text. It is measured by the lexical abstractness formula which is given as:

Number of Abstract Lexical Words

Total Number of Lexical words in the text

\section{$\mathrm{X} 100$}

According to this formula, the lexical abstractness of a text with a total of 60 lexical words and a presence of 40 separate abstract lexical words and functional words predominate will be more difficult to comprehend and appreciate that those in which there are only few lexical or "meaningful" words. In other words, the more lexically abstract a poem, the more difficulty it will be to comprehend and appreciate and the less lexically abstract a poem, the easier it will be to comprehend and appreciate. Our lexical abstractness formula above has been adapted from Arua's (1993) lexical density formula. Arua (1993) has employed lxical density and new 
word density as indices of text readability and used them to rank 72 reaching passages in Books 1-3 of New Practical English Course by Ogundipe and Tregidgo in terms of their readability.

\section{The Differences between Poetry and the Other Literary Genres}

The peculiar nature and characteristics of poetry have been fully illustrated by the various definitions of the subject cited by Osisanwo (1984), Olasehinde (1994) and others. We can only add the fact that poetry is different from prose and drama because it is written in lines mostly of irregular lengths and makes the greatest use of figures of speech such as metaphor, simile, litotes, personification, oxymoron, irony, hyperbole, innuendo and so on. Poetry therefore requires more effort to study and learn than either prose or drama.

Prose is usually concerned with stories, and everyone enjoys stories. Students, teachers and the general readers find stories in the form of novels, short stories and novellas easy to read and understand. It is also common knowledge that students at all levels of any country's educational system perform well in any examination involving this genre. And there are more writers of prose literature than there are of poetry or dramatic works. Drama is characterized by dialogue, which everyone also likes. In dialogue, the distinctive characteristics of drama, one person speaks and another say something in reply. Moreover, both prose and drama are familiar forms. In other words, students come across drama and prose fiction more frequently than they come across poetry.

\section{Other Problems of Poetry}

We have discussed the many values of poetry in this study. However, useful and valuable as poetry is, it must be emphasized that the genre poses serious problems to students. Swatridge (1989) even describes poetry in terms of its difficulty. It (poetry) is the mode of writing that students find most difficult, or least congenial, to talk or write about. Swatridge (1989) proffers the following reasons for the difficulty of poetry among students:

(1) Poetry is an unfamiliar sort of writing: one does not come across poems in the same way that one comes across plays on the television, or stories in Magazines, or letters on one's mat

(2) Poetry seems to speak a private language from which the readers of novels and newspapers are excluded, and critics make matters worse by being solemn about poems as if they were high culture.

Krampah (1979) gives other reasons for the inherent problems of poetry:

(1) There is less objectivity in poetry than there is in prose although both prose and poetry, as creative forms, are first and foremost subjective.

(2) Poetry is a form in compression of ideas, and feeling is the rule rather than the exception.

(3) It is more difficult to get the meaning of a poem than it is to get the meaning of a prose piece.

It is true that poetry is less objective than prose because the former depends far more on feelings, and, as has been pointed out, feelings are by their very nature subjective. Moreover, most poetry communicates in an indirect manner with the result that it is often impossible to say precisely what a poem is about. That is why it is more difficult to get the meaning of a poem than it is to get the meaning of prose passage.

The problems of poetry also have to do with its unconventional punctuation. As all writers of good English very well know, punctuation contributes greatly to the meaning of a written text. However, since punctuation in poetry is unravelling the meaning of a poem is not often forthcoming. Many poems contain anomalous and contradictory sentences. Fromkin and Rodam (1974) give an example of such poem:

As I was going up the stair

I met a man who wasn't there again today

I wish to God he'd go away (p126).

This one-stanza poem contains two complete sentences in three lines, each of the sentences is anomalous. For example, it could not have been possible, as suggested in the first sentence, for anyone to meet on the stair someone "who wasn't there again today", or to wish that the same man "should go away". Unravelling the meanings of anomalous and apparently contradictory sentences in poems will task the comprehension abilities of all but the very bright students. Another example of strange verbal combinations possible in poetry is Dylan Thomas's 'a grief ago'. As Franklin and Rodman (1974) rightly explain, 'ago' is a word ordinarily used with words specified by some temporal semantic feature: 'a week ago', 'a month ago', 'a year ago', 'a century ago' but not 'a grief ago', or 'a farther ago'. When Thomas used the word 'grief' with 'ago' he was adding a durational time feature to the word for poetic effect. (Fromkin and Rodman, 1974). 


\section{Other Factors in the Comprehension and Appreciation of Poetry}

Lexical abstractness is not the only factor that affects the comprehension and appreciation of poetry. The other factors that play a role in this matter are lexical density and new word density. As already noted, lexical words are content or "meaningful" words - words that have meanings. They are so called because their mention calls up the picture of what they denote in the hearer's or reader's mind. The term "density" when used in reference to words, means the level or presence of lexical words. A lexically dense text would therefore mean a text in which content or "meaningful" words are present in large numbers.

Lexical density is the percentage of lexical words in a text. In other words, lexical density refers to the number of lexical words relative to the number of grammatical or function words in a text (Arua, 1993). Arua (1993) gives the following as the formula for calculating the lexical density:

Number of lexical words

Total number of words in the text

$\mathrm{X} 100$

For example, the lexical density of a text with a total number of 50 words and a presence of 10 separate lexical items would be $20 \%$ (10/50 x 100). For example, the lexical density of a text with a total number of 80 words and a presence of 40 separate lexical words would be 50 percent (i.e. $40 / 80 \times 100$ )

As Arua (1993) explains, since lexical items are the main carriers of the information content of a text, the more the lexical words in a text, the more the information load or meaning it carries. Thus, if the percentage of lexical words in a text is high- if there are many lexical items or "meaningful" words in a text, the text is low, the text will most likely be difficult, especially for the average students.

From the two examples of lexical density given above, it could safely be assumed that a poem with a lexical density of $50 \%$ will be easier to comprehend and appreciate than one with a lexical density of $20 \%$. It should be very well noted that Ure (1971) is among the first studies known to the present researcher on the lexical density of texts and that her research is concerned with both spoken and written texts. Her findings show that written texts have on the average a lexical density of over 40 percent while spoken texts have on the average a lexical density of under 40 percent (Arua, 1993: 370).

A third factor that affects the comprehension and appreciation of poetry or of any text is new word density, which is the percentage of new or unknown words in the text (Arua, 1993). The formula for measuring new word density in a text is given by Arua (1993: 372) as:

Number of new / unknown words

Total number of words in the text

X 100

Arua (1993) refers to several studies which show that unfamiliar vocabulary has a negative effect on the comprehension of texts. Thus, if a poem contains many new or unfamiliar words, it will be difficult to comprehend and appreciate.

\section{Conclusion}

Of the three main genres of literature, the one which students find most difficult to comprehend and appreciate and which even many teachers find difficult to teach is poetry. Three factors have been identified in this study as affecting the comprehension and appreciation of poetry: lexical abstractness, lexical density and new word density. Previous studies on these factors are reviewed and our contention and assumptions are that lexically abstract poems as well as poems in which there are many new novel or unknown words will pose difficulty to students and the general readers in terms of comprehension and appreciation. It is suggested that the teacher of poetry who wishes to succeed in his teaching- learning task must take these factors into consideration before presenting this literary genre to students.

\section{References}

Abiola, O. (2014). Poetic Aesthetics in Modern African Poetry.Ilesa Journal of Linguistics and Literary Studies b (1) 11-18. 
Arua, E. (1993). Lexical Density, New word Density and the Readability and Sequencing of Reading Materials in an ESL Course Series. Literacy and Reading in Nigeria. 6, 367-386.

Ayoola, K.A. (2007). University English for all Students. Lagos: Olivertree Publishing Venture.

Bright, J.A. and McGregor, G.P. (1980).Teaching English as a Second Language.London: Longman Group Ltd, 1980.

Faniran, A.O. (1994). Comprehension and Summary for School and Colleges.Ikorodu: JazIroko publishers Ltd.

Faniran, A,O. (2004). Influence of Lexical Density and Abstractness on Nigeria Secondary School Students' Comprehension and Appreciation of Poetry in English(unpublished Ph.D Thesis, University of Ilorin).

Faniran, O.A. (1989). Genre Preference in Literature in English Among Teachers and Students of Literature in Selected Secondary Schools in Ekiti South L.G.A. of Ondo State. An Unpublished PDGE Dissertation, Faculty of Education, University of Ilorin.

Francis, W.N. (1970). The English Language: An Introduction.London: The English Universities Press Ltd.

Fromkin, V. and Rodman, R. (1974). An Introduction to Language London: Holt Rinehart and Winston IncIgudia O. Ibitola, A.O. (2009). Essential literature - in - English.Ibafo: Tonad Publisher Ltd.

Igudia, O. (2015). Language, Themes and Styles in Nigerian Children Children's Literature. In Kamalu, I. and Tamunobelema, I. (2015) (ed) Issues in the Study of Language and Literature: Theory and Practice. Ibadan: Kraft Books Ltd.

Iziyon, A.A, (1987). Comprehensive Notes, Questions and Answers on Selected Poems. Nigeria: Alaanukitan Press Ltd, 1987.

Krampah, D.E.K. (1979). Helping with Literature.Tema: Ghana Publishing Corporation.

Okesipe, K. and Okolo, M.S.C. (2013).Essentials of communication for Nigerian Universities. Ibadan: Rebuttal Books.

Olasehinde, M.O. (1993). Introduction to Literature.In AlabiV.A. (ed). English Language and Principles of Communication. Ilorin: Unilorin Press.

Osisanwo, W. (1984).Preparing the Secondary School Teacher of English for the teaching of Poetry.Journal of English studies 1, 60-70.

Oxford Advanced learners Dictionary (International Student's Edition) (2015). Oxford: Oxford Publishers Limited.

Oyetunji, N.O. (1976). Principles and Practice of teaching English in West Africa. Ibadan.

Swatridge, C. (1989) Alternative Literature Coursework. London: Stanley Thorres Publishers Ltd.

Tucker, B. (1973). Teaching English in the Middle Years. London: Ward Lock Educational

Ure, J. (1971). Lexical Density and Variety Differentiation.In G. Perren\& J. Trim (eds). Applications of Linguistics (paper from the $2^{\text {nd }}$ ALA congress pp 15-30) Cambridge University Press.

Vincent, T. (1979). The Teaching of Modern Africa Poetry in Schools and Colleges. In Ubahakwe (ed) The teaching of English Studies. Ibadan: Ibadan University Press.

Yule, G. (1994). The Study of Language: An Introduction. Cambridge: Cambridge University Press. 